\title{
Roof of the Fourth Ventricle
}

National Cancer Institute

\section{Source}

National Cancer Institute. Roof of the Fourth Ventricle. NCI Thesaurus. Code C33494.

The upper or dorsal portion of the fourth ventricle formed by a section of the superior peduncles of the cerebellum, the superior and inferior medullary velum, the tela choroidea inferior, the obex, and the ligula. 